\title{
Appropriateness of empiric antimicrobial therapy with imipenem/colistin in severe septic patients: observational cohort study
}

\author{
Ahlem Trifi ${ }^{1,2^{*}}$, Sami Abdellatif ${ }^{1,2}$, Cyrine Abdennebi ${ }^{1,2}$, Foued Daly ${ }^{1,2}$, Rochdi Nasri ${ }^{1,2}$, Yosr Touil $^{1,2}$ \\ and Salah Ben Lakhal ${ }^{1,2}$
}

\begin{abstract}
Background: Empiric antimicrobial therapy (EAMT) using imipenem/colistin is commonly prescribed as a first line therapy in critically ill patients with severe sepsis. We aimed to assess the appropriateness of prescribing imipenem/ colistin as EAMT in ICU patients.

Methods: A 3-year observational prospective study included ICU patients that required imipenem/colistin as EAMT. The EAMT was assessed according to microbiological and clinical outcomes. The outcomes were: delay in apyrexia, delay in the decrease of the biological inflammatory parameters (BIP), the requirement for vasoactive agents, bacteriological eradication, length of stay, ventilator days and 30-day mortality.

Results: 79 administrations of EAMT in 70 patients were studied. EAMT was appropriate in $52 \%$ of the studied cases. An ICU stay $>6$ days was related to inappropriateness, and chronic respiratory failure was associated with appropriateness. In the appropriate EAMT group, we showed: earlier apyrexia, shorter delay in the decrease of the BIP and a reduced significant vasopressors requirement. Furthermore, EAMT improved survival with a median gain of 4 days. Inappropriate EAMT increased the mortality risk by six. The acquisition of $\mathrm{NI}$ in ICU was also an independent factor of mortality.
\end{abstract}

Conclusions: EAMT using imipenem-colistin was appropriate in half of the cases and inappropriateness was associated with an increased ICU mortality risk.

Keywords: Empiric, Antimicrobial, Nosocomial sepsis, Imipenem, Colistin, Intensive care, Outcome

\section{Background}

Intensive care unit (ICU) acquired nosocomial infections (NI) have increased rapidly in recent years [1]. EPIC II study in 2007 [2] reported a prevalence of $51 \%$ significantly higher than the previous EPIC I study of $20 \%$ [3]. The pathogens which cause the most are multidrug-resistant (MDR) Gram-negative bacilli (GNB) [4]. Despite the extreme variation of antimicrobial resistance rates between hospitals and countries, there is significant evidence that resistance rates are steadily increasing

\footnotetext{
*Correspondence: trifiahlem2@gmail.com

${ }^{1}$ Medical Intensive Care Unit, University Hospital Center La Rabta, La Rabta Jebbari, 1007 Tunis, Tunisia

Full list of author information is available at the end of the article
}

[5-7]. Worldwide as in Tunisia, three "leaders" of MDRGNB were often reported: Enterobacteria (mainly the extended-spectrum beta lactamase (ESBL) secreting and emergence of carbapenemase-producing strains), Acinetobacter spp. and Pseudomonas aeruginosa [4, 8-13].

Infections due to these microorganisms are associated with a prolonged ICU stay, longer ventilator days, higher mortality and increased health care costs $[1,4]$ with very limited therapeutic options [9, 12-14]. In ICU patients, the occurrence of nosocomial sepsis without bacterial documentation should indicate an early Empiric Antimicrobial Therapy (EAMT). The choice of EAMT is based on the local ecology and the susceptibility profile of isolates. Therefore, EAMT must target the most frequent MDR-GNB previously cited. At present, therapeutic 
options include carbapenems and polymyxins. Carbapenems are a heterogeneous group of $\beta$-lactams with a very broad anti-bacterial spectrum and constitute an unavoidable part of EAMT in severe NI. Their bactericidal activity is related to the connection to penicillin binding proteins, resulting in lysis of endotoxins secreted by GNB [15]. Polymyxins are considered as "old generation" but their therapeutic use has undergone renewed interest owing to the emergence of MDR strains. Its mechanism of action, not fully elucidated, is linked to a polycationic effect disorganizing the phosphate groups of lipopolysaccharides of the GNB's membrane. The association between imipenem provides a synergy of action and thus improves the bactericidal effect. But what about the clinical impact of this association, the most common prescribed EAMT in ICU patients with severe NI?

Herein, we aimed to analyze the characteristics of EAMT with imipenem-colistin and to evaluate its impact on clinical and microbiological outcomes.

\section{Patients and methods Study design}

A prospective observational cohort study with analytical approach over a 36-month period (June 2014 to June 2017). The study was in accordance with the ethical standards of the declaration of Helsinki and approved by the local ethics committee of la Rabta hospital. Given the non-interventional nature, informed consent was not required. All patients or their families were informed of their participation in the study.

\section{Studied population}

Studied population were enrolled, all patients older than 18 years hospitalized in our ICU for at least $48 \mathrm{~h}$ and required EAMT with imipenem/colistin. The criteria for suspicion of NI caused by MDR-GNB were: (1) severe sepsis in a patient without known infection, (2) severe sepsis in a patient treated by antimicrobials other than imipenem/colistin, (3) persistence of a fever $\left(>38{ }^{\circ} \mathrm{C}\right)$ or hypothermia $\left(<36{ }^{\circ} \mathrm{C}\right)$ with an increase of biological inflammatory parameters in a patient receiving antimicrobials well conducted for at least $72 \mathrm{~h}$.

Microbiological samples were taken before the administration of imipenem/colistin. Subsequently, the patients were analyzed in two groups according to whether this EAMT with imipenem/colistin was appropriate versus not. Patients who died within $72 \mathrm{~h}$ of inclusion were excluded.

\section{Definitions}

The different septic states (severe, severe sepsis and septic shock) were defined according to 2014s guidelines
[16] given that the study was started before the updating of sepsis-2016.

EAMT was considered appropriate if it targeted, effectively, an MDR-GNB susceptible to imipenem/colistin accompanied with an improvement of infectious signs. In the absence of bacteriological documentation, improvement of infectious signs defined the appropriateness nature. As a result, this EAMT was kept. EAMT was considered inappropriate in the following situations:- the isolated microorganism as the cause of NI was resistant to imipenem/colistin,-worsening of infectious signs due to other agents (non-GNB or yeasts),-worsening of infectious signs without microbiological documentation,- the isolated microorganism had a multi-sensitive profile leading to de-escalation. Therefore, EAMT was changed, extended or de-escalated. Improvement of the clinical signs was judged on apyrexia and the regression of the infectious signs within $72 \mathrm{~h}$ of initiating EAMT.

\section{Microbiological techniques}

All isolates from various samples (blood cultures, urine, protected distal samples, sputum, drains and catheters...) were included. The strains were isolated on blood agar, chocolate agar, cemetol agar, King A and King B agar. The identification was performed according to standard microbiology techniques (Gram stain, oxidase and mobility) and biochemical characters using API 20NE galleries (BioMérieux, France). Sensitivity to imipenem was determined by the standard Mueller-Hinton agar diffusion method according to the CA-SFM recommendations. The antibiograms were read using the automated Osiris system. Intermediate susceptibility isolates to imipenem were classified as resistant.

Sensitivity to colistin was determined by the E test, and the isolated strain was considered sensitive when the minimum inhibitory concentration (MIC) was less than $2 \mathrm{mg} / \mathrm{L}$. Microbiological eradication was defined as a negative culture.

\section{Data collection}

We recorded and followed all bacteriological and biological data for the patients as well as the issue of EAMT: maintained, changed, extended or de-escalated and the reasons for modification and patient's outcome.

\section{Outcome's criteria}

Outcome's Criteria were delay in apyrexia, decrease of inflammatory parameters, vasoactive agent requirements, bacteriological eradication, length of stay, ventilator days and 30-day mortality. 


\section{Statistical analyzes}

Quantitative variables were expressed as a mean and standard deviation (SD) or a mean and interquartile range [IQR 25th-75th] and compared using the Student's t-test or ANOVA (analysis of variance) method. Categorical variables were expressed as percentages and compared using the $\mathrm{X}^{2}$ test or Fisher's exact test as appropriate.

Logistic regression was used to evaluate the factors associated with appropriate EAMT and between appropriate EAMT and survival. The covariates included were: age, sex, severity scores, medical versus nonmedical admission, co-morbidities, shock, mechanical ventilation, and other parameters. The results are expressed in odds ratio (OR) with a 95\% confidence interval (CI). The survival analysis was processed by the Kaplan-Meier curves and compared by the Log-Rank test. A p value $<0.05$ was fixed for significance. Data analysis was performed using the Statistical Package for Social Sciences (SPSS) version 2.0 software.

\section{Results}

\section{Study flowchart and patient's characteristics}

79 suspicions of NI caused by MDR-GNB were recorded in 70 patients and received imipenem/colistin as EAMT. NIs were documented in 62 cases. Note that one case may correspond to one or more NI and may be caused by one or more pathogens. Based on clinical, biological and bacteriological outcomes, EAMT with imipenem/colistin $(n=79)$ had four issues: kept as initially prescribed $(n=41)$, enlarged by addition of other antimicrobial or antifungal $(n=22)$, modified by other antimicrobials $(n=9)$ and de-escalated $(n=7)$. Figure 1 details the study flowchart and all clinical characteristics are summarized in Table 1.

\section{EAMT details}

Hemodynamic worsening and/or persistence of infectious signs (in patients already receiving antimicrobials other than imipenem/colistin combination) were the most common reason of EAMT administration (81\%). Once NI was suspected, the delay in starting EAMT (mn) did not differ between groups (appropriate EAMT: $32 \mathrm{mn}$ versus inappropriate EAMT: $38 \mathrm{mn}$, $\mathrm{p}=0.91)$ or between subgroups $(\mathrm{p}=0.3)$.

\section{Microbiological results}

Bacteriological results were positives in $62 / 79$ cases within a mean delay of 5 days. Note that diagnosed NI could have one or more locations and could be caused by one or more pathogens. VAP was the major NI location and Acinetobacter baumannii was the main isolate. All microbiological details are displayed on Table 2.

\section{Factors influencing appropriateness of EAMT}

The length of stay (LOS) before NI acquisition was similar between the two groups but differed between the subgroups (mean durations (days) were at 10 [7-13], 8 [4-11], 5 [3-10] and 5 [3-7] respectively in enlargement, change, appropriate and de-escalation subgroups with $\mathrm{p}=0.022$.

Logistic regression (NB: inappropriate EAMT was the case group and appropriate EAMT was the control group) showed that LOS pre-NI acquisition $>6$ days was associated with inappropriateness of EAMT $(\mathrm{OR}=4.44$, 95\% CI [1.06-20.4], $\mathrm{p}=0.05)$. On the other hand, chronic respiratory failure was a factor associated with appropriateness of this EAMT $(\mathrm{OR}=0.26,95 \%$ CI [0.075-0.93], $\mathrm{p}=0.038)$ (Table 3).

\section{Impact of EAMT on a patient's outcome}

- Delay to apyrexia was shorter in the appropriate EAMT group. Mean delays to apyrexia differed between subgroups; the most prolonged delay was observed with the enlargement subgroup. Likewise, the time to decrease the biological inflammatory parameters (BIP) was more rapid in the appropriate EAMT group (Fig. 2a).

- The microbiological follow up showed that bacterial eradication rates were similar either at day 7 or at day 14 of (Fig. 2b).

- Vasopressors requirement was significantly superior in the inappropriate EAMT group with a mean duration of 8 days [6-14] versus 5 days [2-8] in the appropriate EAMT group, $\mathrm{p}=0.026$.

- There were no differences in ventilator days and in ICU stays between appropriate versus inappropriate EAMT ( $15 \pm 5.9$ vs $18 \pm 7$ days, $\mathrm{p}=0.5$ and $22 \pm 12$ vs $29 \pm 15$ days, $p=0.37$ respectively). Between subgroups, patients with changed or enlarged EAMT had higher ventilator days and LOS.

- Thirteen patients in the appropriate EAMT group died (32\%) compared to 20 (52\%) in the inappropriate EAMT group with a near-significant difference $(p=0.071)$. Between subgroups, mortality was higher in the enlargement (59\%) and modification (56\%) comparatively to de-escalation (28.5\%) subgroups.

- The survival analysis showed that appropriate EAMT improved survival at 30 days with a mean time of 25 days [23-28] compared to 21 days [19-24] and $\mathrm{p}=0.058$ (Fig. 2c). 


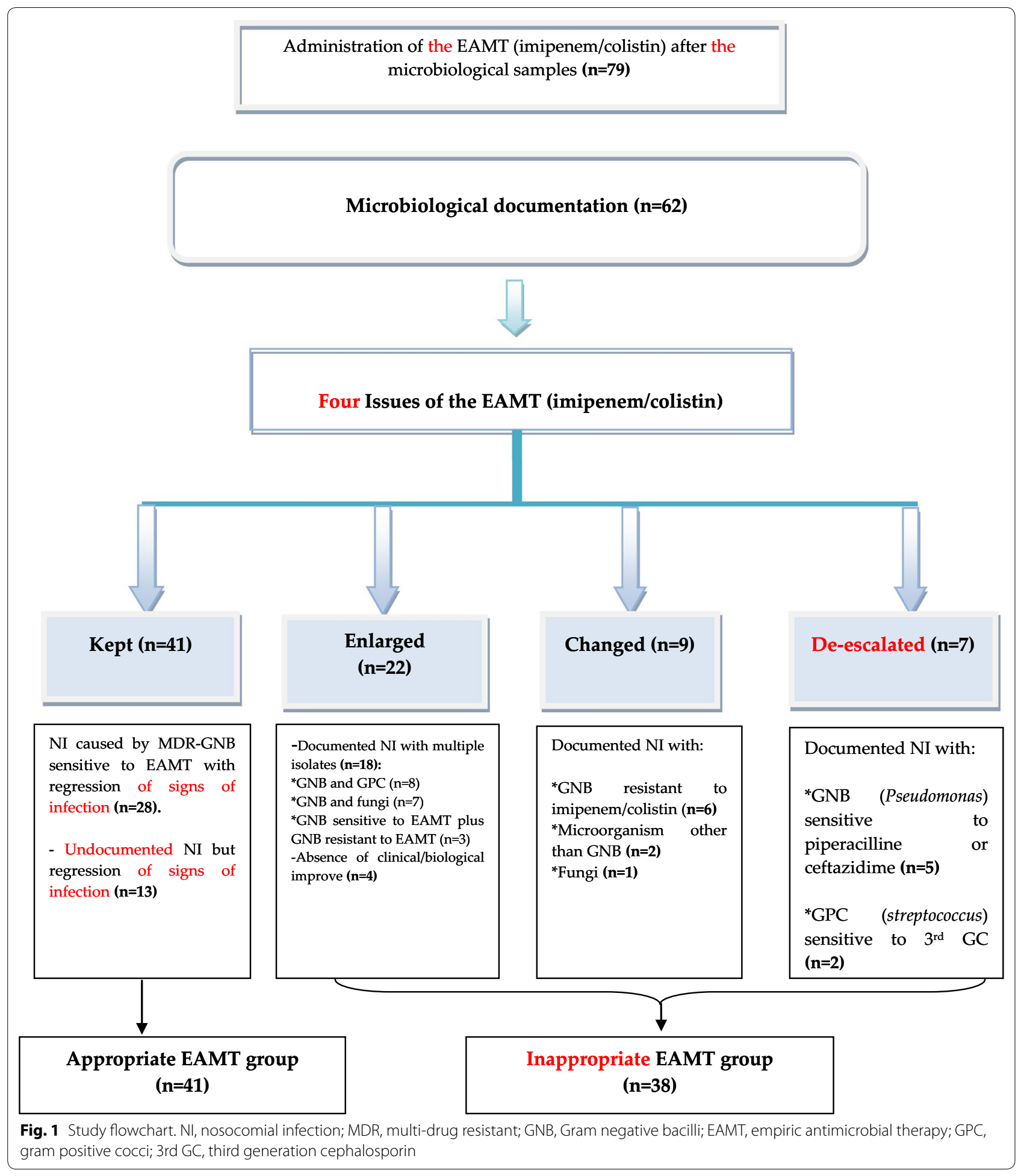

- Inappropriate EAMT was significantly related to mortality $(\mathrm{OR}=6.27,95 \% \mathrm{CI}[1.83-21], \mathrm{p}=0.003)$. When NI was acquired in ICU, the death rate doubled $(\mathrm{OR}=2.02, \quad 95 \%$ CI [1.37-12.12], $\mathrm{p}=0.04)$ (Table 4).

\section{Discussion}

\section{Main findings}

EAMT was appropriate only in $52 \%$ of studied cases. A LOS before NI acquisition beyond 6 days was independently related to inappropriateness contrary to a 
Table 1 Baseline patient's characteristics

\begin{tabular}{|c|c|}
\hline & $\begin{array}{l}\text { Studied } \\
\text { cases } \\
(n=79)\end{array}$ \\
\hline Age (years), mean \pm SD & $53 \pm 17$ \\
\hline Sex-ratio & 1.15 \\
\hline SAPS $\|$, mean $\pm S D$ & $37 \pm 15$ \\
\hline SOFA, mean $\pm S D$ & $5 \pm 3$ \\
\hline \multicolumn{2}{|l|}{ Origin, n (\%) } \\
\hline Emergency department & $46(58 \%)$ \\
\hline Intra-hospital medical department & $21(27 \%)$ \\
\hline Intra-hospital surgical department & $8(10 \%)$ \\
\hline Private healthcare & $4(5 \%)$ \\
\hline \multicolumn{2}{|l|}{ Reason of admission, n (\%) } \\
\hline Acute respiratory failure & $44(56 \%)$ \\
\hline Coma & $22(27 \%)$ \\
\hline Shock & $6(8 \%)$ \\
\hline Infectious disease & $6(8 \%)$ \\
\hline Metabolic disorder & $1(1 \%)$ \\
\hline \multicolumn{2}{|l|}{ Co-morbidities, n (\%) } \\
\hline Diabetes & $31(39 \%)$ \\
\hline Hypertension & $27(34 \%)$ \\
\hline Chronic respiratory failure & $27(34 \%)$ \\
\hline Cardiovascular disease & $14(18 \%)$ \\
\hline Chronic renal failure & $6(7.5 \%)$ \\
\hline Immunosuppression and neoplasia & $6(7.5 \%)$ \\
\hline Length of stay before inclusion, days (median [IQR]) & $6[4-13]$ \\
\hline Prior antimicrobials, n (\%) & $64(81 \%)$ \\
\hline Steroids, n (\%) & $10(13 \%)$ \\
\hline Mechanical Ventilation, n (\%) & $77(97.5 \%)$ \\
\hline Recent surgery, $\mathrm{n}(\%)^{\mathrm{a}}$ & $14(18 \%)$ \\
\hline Tracheostomy, n (\%) & $33(42 \%)$ \\
\hline
\end{tabular}

SD, standard derivation; SAPS, Simplified Acute Physiology Score Evaluation; SOFA, Sequential Organ Failure Assessment

a During the last 6 months

history of chronic respiratory failure that was associated to appropriateness. Appropriate EAMT improved clinical and biological evolution and 30-day survival. Moreover, inappropriateness increased ICU risk mortality by six.

\section{Rational of empiric antimicrobial therapy using imipenem/ colistin}

Expert recommendations emphasize the quality and appropriateness of empiric antibiotics, especially in severe sepsis $[17,18]$. Among the major pathogens in the cause of ICU-NI, Pseudomonas aeruginosa has the potential to become resistant to all antibiotics because of its ability to create bio-films and overexpression of AmpCB-lactamases and metallo-B-lactamases MBLs [7]. Acinetobacter spp. has multiple mechanisms for horizontally developing and transferring resistance, the most important of which are the production of $\beta$-lactamases and the modification of aminoglycoside enzymes. For enterobacterial isolates, the spread of the strain that produces extended-spectrum $\beta$-lactamases (ESBLs) has been reported worldwide. Carbapenems have become the best and last drug for treatment; contributing to the increase of carbapenem resistance by Enterobacteriaceae (CRE). In China, carbapenem-resistant Klebsiella pneumoniae was the main isolate among CRE due to the production of $b l a_{I M P-4}$ and armA genes [8].

These three pathogens were the most isolates in our series, which justified the choice of imipenem/colistin combination as a first-line therapy. The screening of MDR strains can guide the clinician to initiate appropriate empiric therapy $[19,20]$. Likewise, the fluid circulation of information and even the creation of a multidisciplinary communication network (bacteriologist, clinician, pharmacologist, etc.) is an approach that helps to optimize the "best choice " of the initial antimicrobials.

Because standard bacteriologic methods are time consuming, molecular techniques namely PCR amplifications have shown to be a rapid and reliable approach for the identification of bacterial pathogens [21-25]. Several PCR-based methods have been described to identify $P$. aeruginosa [22], Acinetobacter baumannii [23, 24], and ESBL-producing Escherichia coli [25]. Most studies in this topic concur that this novel strategy offers a rapid $(<1.5 \mathrm{~h})$ tool for clinicians to initiate an appropriate treatment earlier compared to phenotypic methods. In Tunisia, PCR amplification methods are not performed routinely; it is done during investigation of an epidemic infection [26].

The time to obtain bacteriological results was overall 5 days in our study and in the absence of the practise of these novel techniques routinely, an empiric prescription of imipenem/colistin remains judicious.

The subsequent control of EAMT is a crucial step in the best practices of antimicrobials use. Leone et al. [27] showed that de-escalation was safe and associated with lower antibiotic use and shorter antibiotic duration; and theoretically a beneficial effect on the MDR emergence $[27,28]$. Leone et al. [27] reported an appropriateness rate of $89 \%$ in cases [including de-escalation (42\%)] [27]. In our series, de-escalation was only possible in $7 / 79(9 \%)$ of initial prescriptions, given the predominance of MDR strains. We opted for considering de-escalation as inappropriate because this "excessive" regimen threatens the future efficiency of the current available antibiotics.

Nonetheless, De Bus et al. [29] analyzed the effect of de-escalation on 478 prescriptions for anti-Pseudomonas antibiotics and found no lower levels of resistant strains after exposure to broad-spectrum B-lactams. 
Table 2 Microbiological data in study groups

\begin{tabular}{|c|c|c|c|c|}
\hline \multirow[t]{2}{*}{ Subgroups } & \multirow{2}{*}{$\begin{array}{l}\text { Appropriate } \\
\text { EAMT group } \\
(n=41)\end{array}$} & \multicolumn{3}{|c|}{ Inappropriate EAMT group $(\mathrm{n}=38)$} \\
\hline & & Enlargement $(n=22)$ & Change $(n=9)$ & De-escalation $(n=7)$ \\
\hline Bacteriologic documentation, $\mathrm{n}$ & $28 / 41$ & $18 / 22$ & $9 / 9$ & $7 / 7$ \\
\hline \multicolumn{5}{|c|}{ NI location } \\
\hline VAP & 22 & 11 & 2 & 4 \\
\hline Bacteraemia & 3 & 7 & 3 & 2 \\
\hline CRI & 2 & 5 & 3 & 0 \\
\hline CRB & 1 & 1 & 0 & 1 \\
\hline $\mathrm{UI}$ & 0 & 1 & 1 & 0 \\
\hline \multicolumn{5}{|l|}{ Isolates (n) } \\
\hline Acinetobacter $B$ & 14 & 6 & 0 & 0 \\
\hline Klebsiella pneumonia & 6 & 4 & 0 & 0 \\
\hline Pseudomonas spp. & 5 & 5 & 3 & 5 \\
\hline Enterobacter & 2 & 4 & 1 & 0 \\
\hline E. coli & 0 & 1 & 0 & 0 \\
\hline Staphylococcus & 0 & 4 & 1 & 0 \\
\hline Enterococcus & 0 & 3 & 1 & 0 \\
\hline Stenotrophomonas M & 0 & 3 & 2 & 0 \\
\hline Burkholderiacepacia & 1 & 0 & 0 & 0 \\
\hline Streptocoque spp. & 0 & 0 & 0 & 2 \\
\hline Candida species & 0 & 7 & 1 & 0 \\
\hline \multirow[t]{3}{*}{ Antimicrobial adjustment } & \multirow[t]{3}{*}{ Imipenem/colistin } & $\begin{array}{l}\text { Imipenem/colistin/Glycopeptid } \\
(\mathrm{n}=8)\end{array}$ & $\begin{array}{l}\text { Other betalactam (for resistance to } \\
\text { impenem) }+ \text { tygecycline, amino- } \\
\text { glycoside or quinolone }(n=6)\end{array}$ & Piperacilline $(n=2)$ \\
\hline & & $\begin{array}{l}\text { Imipenem/colistin/antifungal } \\
(n=7)\end{array}$ & Glycopeptide \pm aminoside $(n=2)$ & Ceftazidime $(n=3)$ \\
\hline & & $\begin{array}{l}\text { Imipenem/colistin/Tygecycline/ } \\
\text { aminglyosides }(n=3)\end{array}$ & Antifungal $(n=1)$ & Cefotaxime $(n=2)$ \\
\hline
\end{tabular}

EAMT, empiric antimicrobial therapy; NI, nosocomial infection; VAP, ventilator acquired pneumonia; CRI, catheter related infection; CRB, catheter related bacteraemia; UI, urinary infection

\section{Factors influencing appropriateness of EAMT}

Several observational studies demonstrated that the use of antimicrobial combinations is superior than monotherapy [30,31]. The probable infection site is also an influencing factor involved in the appropriateness of empiric therapy. It should guide the choice of antimicrobials capable of reaching the therapeutic concentrations in the infected tissues and fluids. An American multicenter cohort study revealed that nosocomial pneumonia and urinary tract infection had the greatest variation for appropriate use $(50-100 \%$ for nosocomial pneumonia and $64.9-100 \%$ for urinary tract infection) [32]. In our series, no influence was showed in the probable site of NI.

Chronic co morbidities, immune status and social history (frequent travel, incarceration, illicit drug use...) should also be taken into account [33]. We found that a history of chronic respiratory failure (CRF) was significantly associated with appropriate EAMT. Even if it is considered as an unexpected result; patients with CRF could be carried by MDR (not necessarily identifiable) due to their frequent hospitalizations for exacerbation. In this case, imipenem/colistin the combination would play a key role in improvement.

Otherwise, hospitalization $>6$ days was an independent factor associated with inappropriateness in our series. This should encourage the reconsideration of non-GNB or GNB with a special susceptibility profile in the choice of EAMT. That concerned mainly GPC or strains with potential acquisition of resistance to imipenem (such Pseudomonas, acinetobacter...) or selected organisms with a natural resistance to colistin (Proteus, Providencia...). No effect was found for previous antimicrobial use, recent surgery, shock or age. For Paul et al. [31] shock was associated with adequate empiric therapy. Willemsen et al. [34] showed that the use of quinolones was the only determinant of inappropriateness [34].

Several studies have emphasized the "timing" for antimicrobial initiation [35, 36]. For Luna, et al. [29], patients classified in the inappropriate arm received 
Table 3 Factors influencing appropriateness or not of EAMT

\begin{tabular}{|c|c|c|c|c|c|c|}
\hline & \multirow{2}{*}{$\begin{array}{l}\text { Appropriate } \\
\text { EAMT }(n=41)\end{array}$} & \multirow{2}{*}{$\begin{array}{l}\text { Inappropriate } \\
\text { EAMT }(n=38)\end{array}$} & \multirow[t]{2}{*}{ p } & \multicolumn{3}{|c|}{ Logistic regression results } \\
\hline & & & & OR & $95 \% \mathrm{Cl}$ & $\mathrm{p}$ \\
\hline Age, years (mean $\pm S D$ ) & $50 \pm 18$ & $55 \pm 16$ & 0.18 & & & \\
\hline Age $>50$ years, $\mathrm{n}(\%)$ & $22(53 \%)$ & $26(68 \%)$ & 0.2 & 2.4 & {$[0.67-8.51]$} & 0.17 \\
\hline Sex-ratio & $26 / 15$ & $21 / 17$ & 0.49 & & & \\
\hline SAPS ॥ & $36 \pm 14$ & $40 \pm 16$ & 0.26 & & & \\
\hline SOFA & $5.2 \pm 2.9$ & $6.5 \pm 3.7$ & 0.076 & & & \\
\hline SOFA > 5, n (\%) & $14(34 \%)$ & $20(52 \%)$ & 0.13 & 1.66 & {$[0.54-5.06]$} & 0.36 \\
\hline \multicolumn{7}{|l|}{ Origin of $\mathrm{Nl}$ acquisition } \\
\hline Medical ICU & $9(22 \%)$ & $14(37 \%)$ & 0.18 & 0.61 & {$[0.10-3.64]$} & 0.6 \\
\hline$E D^{*}$ & $22(53 \%)$ & $15(39 \%)$ & 0.20 & 1.14 & {$[0.30-4.33]$} & 0.84 \\
\hline Medical department & $5(12 \%)$ & $8(21 \%)$ & 0.32 & & & \\
\hline Other & $5(12 \%)$ & $1(2.6)$ & - & & & \\
\hline \multicolumn{7}{|l|}{ Co-morbidities } \\
\hline Diabetes & $17(41 \%)$ & $14(37 \%)$ & 0.36 & 0.26 & {$[0.075-0.93]$} & 0.038 \\
\hline Chronic respiratory failure & $19(46 \%)$ & $8(21 \%)$ & 0.032 & 1.42 & {$[0.43-4.67]$} & 0.56 \\
\hline Immunosuppression/neoplasia & $7(17 \%)$ & $6(16 \%)$ & 0.99 & & & \\
\hline Cardiovascular disease & $17(41 \%)$ & $24(63 \%)$ & 0.079 & & & \\
\hline \multicolumn{7}{|l|}{ Nature of suspected NI: } \\
\hline VAP & $33(80 \%)$ & $26(68 \%)$ & 0.2 & 0.6 & {$[0.19-1.94]$} & 0.40 \\
\hline Bloodstream infection & $6(15 \%)$ & $6(16 \%)$ & - & & & \\
\hline CRI & $2(5 \%)$ & $5(13 \%)$ & - & & & \\
\hline UI & 0 & $1(2.6 \%)$ & - & & & \\
\hline LOS pre-NI acquisition, days (med [IQR]) & $5[3-10]$ & $8[6-14]$ & 0.09 & & & \\
\hline LOS pre-NI $>6$ days & $10(24 \%)$ & $20(52 \%)$ & 0.012 & 4.44 & {$[1.06-20.4]$} & 0.05 \\
\hline Prior antimicrobials & $32(78 \%)$ & $32(84 \%)$ & 0.57 & & & \\
\hline Pre-exposure to imipenem & $10(24 \%)$ & $11(29 \%)$ & 0.8 & & & \\
\hline Pre-exposure to beta-lactams (other than imipenem) & $20(49 \%)$ & $18(47 \%)$ & 0.82 & & & \\
\hline Pre-exposure to colistin & $7(17 \%)$ & $8(21 \%)$ & 0.77 & & & \\
\hline Pre-exposure to glycopeptides & $7(17 \%)$ & $4(10.5 \%)$ & 0.52 & & & \\
\hline Recent surgery & $4(10 \%)$ & $10(26.5 \%)$ & 0.061 & 1.69 & {$[0.37-7.66]$} & 0.49 \\
\hline Shock & $16(39 \%)$ & $16(42 \%)$ & 0.82 & & & \\
\hline Mechanical ventilation & $40(97.5 \%)$ & $37(97.3 \%)$ & 1 & & & \\
\hline Tracheostomy & $17(41 \%)$ & $16(42 \%)$ & 0.81 & & & \\
\hline Current corticosteroid & $5(12 \%)$ & $5(13 \%)$ & 1 & & & \\
\hline
\end{tabular}

EAMT, empiric antimicrobial therapy; SD, standard derivation; SAPS, Simplified Acute Physiology Score Evaluation; SOFA, Sequential Organ Failure Assessment; ICU, intensive care unit; $\mathrm{ED}$, emergency department; $\mathrm{NI}$, nosocomial infection; $\mathrm{VAP}$, ventilator acquired pneumonia; $\mathrm{CRI}$, catheter related infection; $\mathrm{UI}$, urinary infection; $\mathrm{LOS}$, length of stay; $\mathrm{QQR}$, interquartile range; $\mathrm{OR}$, odds ratio; $\mathrm{Cl}$, confidence interval

Italic values indicate $\mathrm{p}<0.05$

empiric therapy on a mean delay of $28.6 \pm 5.8 \mathrm{~h}$ versus $12.5 \pm 4.2 \mathrm{~h}, \mathrm{p}<0.01 \mathrm{in}$ inappropriate arm. Leibman et al. developed a prediction score in order to optimize the time and the decision to initiate appropriate therapy for CRE including six items [37]. A score of $\geq 32$ predicted "high CRE risk" and thus indicated an empiric therapy with $90 \%$ of negative predictive value [37].
The time to initiate empiric therapy in our series was rapid and similar for both groups and therefore it wasn't studied as an influential factor.

The retrospective study (2005-2010) of Al-Dorzi et al. [38] assessing the impact of empiric antimicrobial in Acinetobacter bacteraemia identified that female sex, admission during 2008-2010 compared to 2005-2007, mechanical ventilation and age were associated with appropriate therapy [38]. 

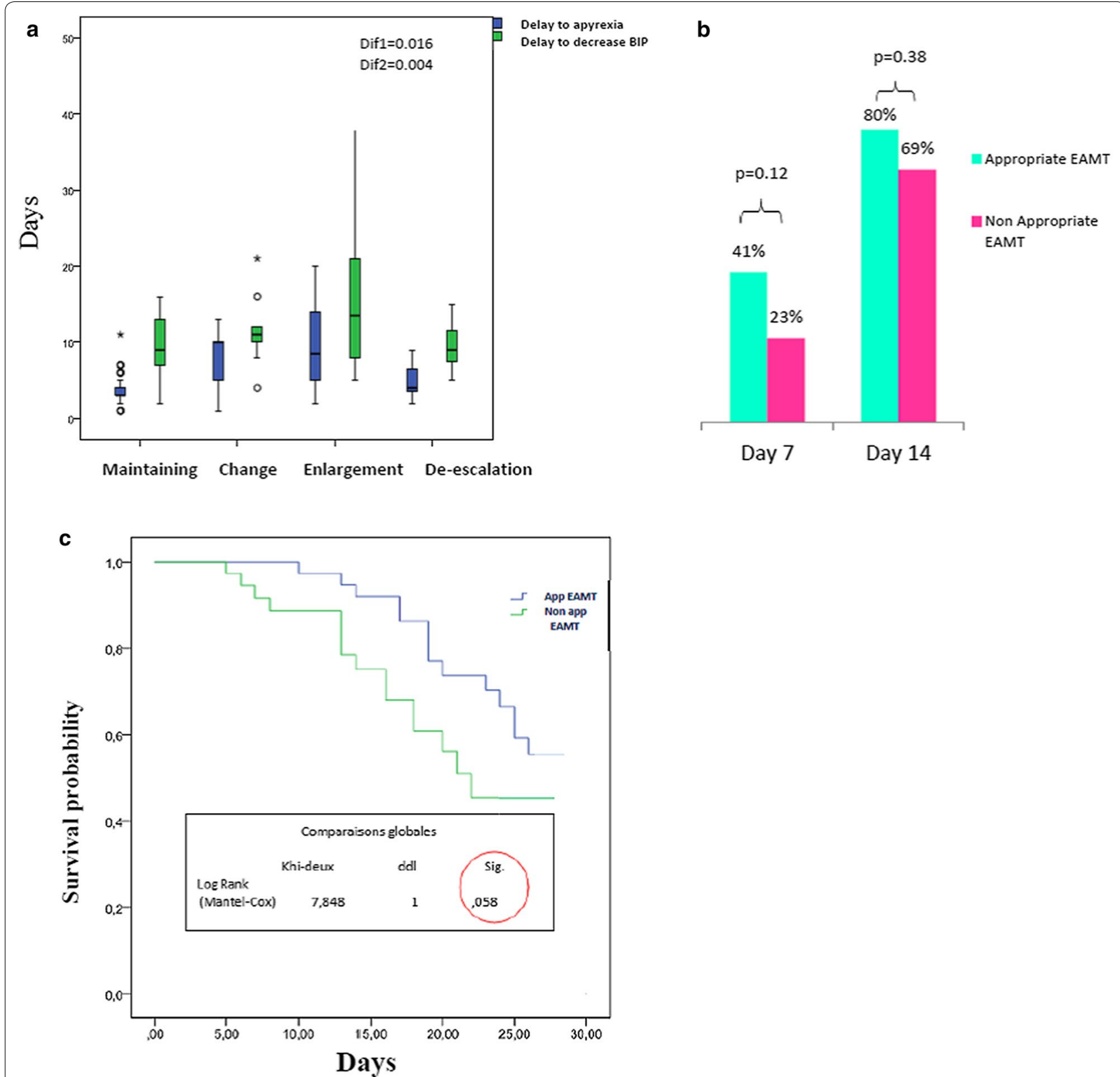

Fig. 2 Comparison of outcome's criteria between study groups. EAMT, empiric antimicrobial therapy; BIP, biological inflammatory parameters; dif1, significance for delay to apyrexia; dif2: significance for delay to decrease BIP

\section{Impact on patient's outcome}

The poor impact of inappropriate initial antimicrobial was widely demonstrated [31, 39-46]. A Spanish multicenter study found that the mortality attributable to appropriate empiric therapy was $16.2 \%$ versus $24.7 \%$ in patients who received inappropriate therapy [41]. A meta-analysis (70 studies) evaluated the efficacy of appropriate empiric antimicrobial therapy for sepsis, showed that inappropriateness of initial therapy was associated with significant mortality $(\mathrm{OR}=2.05,95 \% \mathrm{CI}[1.69-2.49])$
[31]. The large prospective study of Paul et al. [42] including $2000 \mathrm{medical} /$ surgical patients showed that the hospital mortality rate in infected patients who received initial inappropriate therapy was statistically higher $52.1 \%$ versus $12.2 \%$ with $R R=4.26,95 \%$ CI [3.52-5.15]; $\mathrm{p}<0.001$.

Another large systematic review (57 studies) [46] showed that appropriate empiric therapy was associated with a lower mortality risk (OR adjusted $=0.43,95 \% \mathrm{CI}$ $0.23-0.83)$ and lower therapeutic failure $(\mathrm{OR}=0.22,95 \%$ CI 0.14-0.35). In contrast, inappropriate empiric therapy 
Table 4 Factors associated with mortality by logistic regression

\begin{tabular}{|c|c|c|c|c|}
\hline Varieties & Survivors $(n=46)$ & Died $(n=33)$ & OR $[95 \% \mathrm{Cl}]$ & $\mathbf{p}$ \\
\hline Inappropriate EAMT, n (\%) & $18(39 \%)$ & $20(61 \%)$ & $6.27[1.83-21]$ & 0.003 \\
\hline Age, mean $\pm D^{a}$ & $52 \pm 18$ & $54 \pm 16$ & $1.15[0.28-4.64]$ & 0.83 \\
\hline $\mathrm{SOFA}^{\mathrm{a}}$, mean $\pm \mathrm{DS}$ & 5.52 & 6.36 & $1.58[0.79-2.91]$ & 0.37 \\
\hline Chronic respiratory failure, $\mathrm{n}(\%)$ & $16(35 \%)$ & $11(33 \%)$ & $0.87[0.35-2.15]$ & 0.77 \\
\hline Cardiovascular disease, n (\%) & $19(41 \%)$ & $22(66 \%)$ & $1.43[0.56-2.79]$ & 0.25 \\
\hline Diabetes, n (\%) & $19(41 \%)$ & $12(36 \%)$ & $0.77[0.27-1.96]$ & 0.48 \\
\hline ICU acquired NI, n (\%) & $8(17 \%)$ & $15(45 \%)$ & $2.02[1.37-12.12]$ & 0.044 \\
\hline ED acquired NI, n (\%) & $20(43 \%)$ & $17(51 \%)$ & $1.16[0.65-3.37]$ & 0.67 \\
\hline Medical service acquired NI, n (\%) & $9(19 \%)$ & $4(12 \%)$ & $0.62[0.01-1.84]$ & 0.13 \\
\hline Shock, n (\%) & $11(24 \%)$ & $21(63 \%)$ & $1.96[0.87-9.28]$ & 0.09 \\
\hline
\end{tabular}

EAMT, empiric antimicrobial therapy; SOFA, Sequential Organ Failure Assessment; ICU, intensive care unit; ED, emergency department; NI, nosocomial infection; OR, odds ratio; $\mathrm{Cl}$, confidence interval

a Studied variables: age $>50$ years and SOFA $>5$

Italic values indicate $\mathrm{p}<0.05$

increased mortality risk $(\mathrm{OR}=3.30,95 \%$ CI $2.42-4.49)$ [46]. A systematic review and meta-analysis of mortality in patients infected with carbapenem-resistant Klebsiella pneumoniae showed the pooled mortality was $42.14 \%$ versus $21.16 \%$ in those infected with carbapenem-susceptible K. pneumonia [47]. This difference was due to an inappropriate empiric therapy with very limited therapeutic options [47].

In our series, despite the inclusion of a de-escalation subgroup (with the lowest mortality) in the inappropriate EAMT arm, inadequate empiric therapy was significantly related to mortality (OR $=6.27,95 \% \mathrm{CI}[1.83-21]$, $\mathrm{p}=0.003$ ). In addition, the acquisition of NI in ICU was also a significant factor related to mortality. This is explained by the fact that the strains selected in ICU are the most concerned by the multi-resistance to antimicrobials, the high risk of invasive candidiasis, a greater severity and a heavier underlying co-morbidity. All these factors are likely to worsen the patient's prognosis.

Nevertheless, Zaragoza et al. [48] and Falagas et al. [43] did not find a significant relationship between inappropriate empiric therapy and mortality.

Furthermore, inappropriate empiric antimicrobials were associated with higher hospital costs $(\$ 51,977$, [\$ $34,644-\$ 69,311])$ and a prolonged stay hospital (21, [13-21] days) in comparison with an appropriate empiric therapy $(\$ 40,187$, [\$ 25,982-\$54,392]) and (18, [9-24] days) [46].

\section{Strength and weakness}

it is estimated that the strong point of this study is its originality; the imipenem/colistin combination is the antimicrobial therapy used as first choice in front of a nosocomial septic, but is it really the best choice? On the other hand, the therapeutic arsenal with proven efficacy against MDR pathogens is very limited and therefore these molecules should to be preserved by rational use. Hence the need for the assessment of its clinical impact to which this study has responded. To the best of our knowledge, this is the first to evaluate the combination imipenem/colistin as empiric therapy.

The weak points are the mono-centric design and the small sample studied. Another point could be the source of an evaluation bias; which is the inclusion of the deescalation subgroup in the inappropriate EAMT. This is explained by the fact that in this subgroup, EAMT was effective against isolated organisms. However, because of the broad spectrum of this association, a source of selection for resistant mutants, its prescription was considered unjustified. That was the reason why we chose to integrate this subgroup into the inappropriate arm.

\section{Conclusions}

Despite the high proportion of MDR-GNB in the cause of nosocomial sepsis, empiric antimicrobial therapy using imipenem-colistin was only appropriate in half of cases and increased mortality. It would therefore be judicious to revise this empiric therapy with the elaboration of therapeutic regimens according to the duration before $\mathrm{NI}$ acquisition, its location and colonization with MDR bacteria. A multi-disciplinary approach involving clinicians, microbiologist and pharmacologist is paramount to ensure a rational prescription of antimicrobials. The introduction of rapid diagnostic tests, such as PCR techniques, would be a necessary step to reach rapidly and surely the appropriateness of empiric therapy. 


\section{Abbreviations}

EAMT: empiric antimicrobial therapy; NI: nosocomial infection; ICU: intensive care unit; MDR: multidrug-resistant; GNB: Gram-negative bacilli; ESBL: extended-spectrum beta lactamase; LOS: length of stay; BIP: biological inflammatory parameters; GPC: Gram positive cocci; 3rd GC: third generation cephalosporin; SAPS: Simplified Acute Physiology Score Evaluation; SOFA: Sequential Organ Failure Assessment; ED: emergency department; AP: ventilator acquired pneumonia; CRI: catheter related infection; UI: urinary infection; SD: standard derivation; IQR: inter quartile range; OR: odds ratio; $\mathrm{Cl}$ : confidence interval.

\section{Authors' contributions}

AT, SA and CA analyzed, interpreted the data, performed the statistical analysis and drafted the manuscript. CA collected the data and contributed to the written of the manuscript. FD, RN, YT participated in the collection of data and revision of the manuscript. SA and SBL corrected with critical revision of the manuscript. All authors read and approved the final manuscript.

\section{Author details}

${ }^{1}$ Medical Intensive Care Unit, University Hospital Center La Rabta, La Rabta Jebbari, 1007 Tunis, Tunisia. ${ }^{2}$ Faculty of Medicine, University Tunis, El Manar, Tunis, Tunisia.

\section{Acknowledgements}

All the authors warmly thank the professor Gary Skyner for his valuable collaboration in English correction.

\section{Competing interests}

The authors declare that they have no competing interests.

\section{Availability of data and materials}

The datasets generated during and/or analyzed during the current study are available from the author for correspondence on reasonable request.

\section{Consent for publication}

Not applicable.

\section{Ethics approval and consent to participate}

The study was in accordance with the ethical standards of the declaration of Helsinki and approved by the local ethics committee of la Rabta hospital. Given the non-interventional nature, informed consent was not required. All patients or their families were informed by the participation in the study.

\section{Funding}

This research received no external funding.

\section{Publisher's Note}

Springer Nature remains neutral with regard to jurisdictional claims in published maps and institutional affiliations.

Received: 3 July 2018 Accepted: 7 November 2018 Published online: 16 November 2018

\section{References}

1. Paramythiotou E, Routsi C. Association between infections caused by multidrug-resistant gram-negative bacteria and mortality in critically ill patients. World J Crit Care Med. 2016;5(2):111-20.

2. Vincent JL, Rello J, Marshall J, Silva E, Anzueto A, Martin CD, et al. International study of the prevalence and outcomes of infection in intensive care units. JAMA. 2009;302:2323-9.

3. Vincent JL, Bihari DJ, Suter PM, Bruining HA, White J, Wolff M, et al. The prevalence of nosocomial infection in intensive care units in Europe. Results of the European Prevalence of Infection in Intensive Care (EPIC) Study. EPIC International Advisory Committee. JAMA. 1995;274:639-44.

4. Chelazzi C, Pettini E, Villa G, De Gaudio AR. Epidemiology, associated factors and outcomes of ICU-acquired infections caused by Gram-negative bacteria in critically ill patients: an observational, retrospective study. BMC Anesthesiol. 2015;15:125.
5. Cantón R, Akóva M, Carmeli Y, Giske CG, Glupczynski Y, Gniadkowski M, et al. Rapid evolution and spread of carbapenemases among Enterobacteriaceae in Europe. Clin Microbiol Infect. 2012;18:413-31.

6. Petty NK, Ben Zakour NL, Stanton-Cook M, Skippington E, Totsika M, Forde BM, et al. Global dissemination of a multidrug resistant Escherichia coli clone. Proc Natl Acad Sci USA. 2014;111:5694-9.

7. Zilahi G, Artigas A, Loeches IM. What's new in multidrug-resistant pathogens in the ICU? Ann Intensive Care. 2016;6:96.

8. Pang F, Qin Jia X, Gang Zhao Q, Zhang Y. Factors associated to prevalence and treatment of carbapenem-resistant Enterobacteriaceae infections: a seven years retrospective study in three tertiary care hospitals. Ann Clin Microbiol Antimicrob. 2018:17:13.

9. Brusselaers N, Vogelaers D, Blot S. The rising problem of antimicrobial resistance in the intensive care unit. Ann Intensive Care. 2011;1:47.

10. Boucher HW, Talbot GH, Bradley JS, Edwards JE, Gilbert D, Rice LB, et al. Bad bugs, no drugs: no ESKAPE! An update from the Infectious Diseases Society of America. Clin Infect Dis. 2009;48(1):1-12

11. Ktari S, Mnif B, Znazen A. Diversity of $\beta$-lactamases in Pseudomonas aeruginosa isolates producing metallo- $\beta$-lactamase in two Tunisian hospitals. Microb Drug Resist. 2011:17(1):25-30.

12. Chaari A, Mnif B, Bahloul M, Mahjoubi F, Chtara K, Turki O, et al. Acinetobacter baumannii ventilator-associated pneumonia: epidemiology, clinical characteristics, and prognosis factors. Int J Infect Dis. 2013;17:12.

13. Trifi A, Abdellatif S, Oueslati M, Zribi M, Daly F, Ben Lakhal S, et al. Nosocomial infections: current situation in a resuscitation-unit. La Tun Med. 2017;95:179-84.

14. Doyle JS, Buising KL, Thursky KA, Worth LJ, Richards MJ. Epidemiology of infections acquired in intensive care units. Semin Respir Crit Care Med. 2011;32(2):115-38.

15. Wolff M, Joly-Guilloub M-L, Pajot O. Comparative review of carbapenems. Réanimation. 2009:18:S199-208.

16. Cecconi M, De Backer D, Antonelli M, Beale R, Bakker J, Hofer C, et al. Consensus on circulatory shock and hemodynamic monitoring. Task force of the European Society of Intensive Care Medicine. Intensive Care Med. 2014:40:1795-815.

17. Conférence de consensus commune SFAR, SRLF. Prise en charge hémodynamique du sepsis sévère (nouveau né exclu). Paris 2005. Ann Fr Anesth Réanim 2006. 133p.

18. Vincent JL, Marshall JC, Amendys-Silva SA, Francois B, Martin Loeches I, Lipman J, et al. Assessment of the worldwide burden of critical illness: the intensive care over nations (ICON) audit. Lancet Respir Med. 2014:2:380-6.

19. Oostdijk EAN, de Smet AMGA, Kesecioglu J, Bonten MJM. The role of intestinal colonization with gram-negative bacteria as a source for intensive care unit-acquired bacteremia. Crit Care Med. 2011;39:961-6.

20. Brusselaers N, Labeau S, Vogelaers D, Blot S. Value of lower respiratory tract surveillance cultures to predict bacterial pathogens in ventilatorassociated pneumonia: systematic review and diagnostic test accuracy meta-analysis. Intensive Care Med. 2013:39(3):365-75.

21. Zheng F, Sun J, Cheng C, Rui Y. The establishment of a duplex real-time $P C R$ assay for rapid and simultaneous detection of bla $a_{\mathrm{NDM}}$ and bla $a_{\mathrm{KPC}}$ genes in bacteria. Ann Clin Microbiol Antimicrob. 2013;12:30.

22. Cattoir V, Gilibert A, Le Glaunec JM, Launay N, Bait-Mérabet L, Legrand P. Rapid detection of Pseudomonas aeruginosa from positive blood cultures by quantitative PCR. Ann Clin Microbiol Antimicrob. 2010;9:21.

23. Alyamani EJ, Khiyami MA, Booq RY, Alnafjan BM, Altammami MA, et al. Molecular characterization of extended-spectrum beta-lactamases (ESBLs) produced by clinical isolates of Acinetobacter baumannii in Saudi Arabia. Ann Clin Microbiol Antimicrob. 2015;14:38.

24. Andriamanantena TS, Ratsima E, Rakotonirina HC, Randrianirina F, Ramparany $\mathrm{L}$, Carod JF, et al. Dissemination of multidrug resistant Acinetobacter baumannii in various hospitals of Antananarivo Madagascar. Ann Clin Microbiol Antimicrob. 2010;9:17.

25. Alyamani EJ, Khiyami AM, Booq RY, Majrashi MA, Bahwerth FS, Rechkina E. The occurrence of ESBL-producing Escherichia coli carrying aminoglycoside resistance genes in urinary tract infections in Saudi Arabia. Ann Clin Microbiol Antimicrob. 2017:16:1.

26. Battikh H, Harchay C, Dekhili A, Khazar K, Kechrid F, Zribi M, et al. Clonal spread of colistin-resistant Klebsiella pneumoniae coproducing KPC 
and VIM carbapenemases in neonates at a Tunisian University Hospital. Microb Drug Resist. 2017;23:468-72.

27. Leone $\mathrm{M}$, Bechis $\mathrm{C}$, Baumstarck K, Lefrant J-Y, Albanése J, Jaber S, et al. de-escalation versus continuation of empirical antimicrobial treatment in severe sepsis : a multicenter non-blinded randomized noninferiority trial. Intensive Care Med. 2014;40:1339-408.

28. Chterev V, Benbara A, Augustin P, Montravers P. Antibiothérapie probabiliste en réanimation. EMC - Anesthésie-Réanimation 2009:1-12.

29. De Bus L, Denys W, Catteeuw J, Gadeyne B, Vermeulen K, Boelens J, et al. Imact of descalation of beta-lactam antibiotics on the emergence of antibiotic résistance in ICU patients: are trospective observational study. Intensive Care Med United States. 2016;42:1029-94.

30. Micek ST, Welch EC, Khan J, Pervez M, Doherty JA, Reichley RM, et al. Empiric combination antibiotic therapy is associated with improved outcome against sepsis due to Gram-negative bacteria: a retrospective analysis. Antimicrob Agents Chemother. 2010;54:1742-8.

31. Paul M, Shani V, Muchtar E, Kariv G, Robenshtok E, Leibovici L. Systematic review and metanalysis of the efficacy of appropriate empiric antibiotic therapy for sepsis. Antimicrob Agents Chemother. 2010;54:4851-63.

32. DePestel DD, Eiland EH III, Lusardi K, Destache CJ, Mercier RC, McDaneld PM, et al. Assessing appropriateness of antimicrobial therapy: in the eye of the interpreter. Clin Infect Dis. 2014;59(S3):S154-61.

33. Mastertona R, Drusanob G, Patersonc DL, Parkd G. Appropriate antimicrobial treatment in nosocomial infections-the clinical challenges. J Hosp Infect. 2003;55:1-12.

34. Willemsen I, Groenhuijzen A, Bogaers D, Stuurman A, Van Keulen P, Kluytmans J. appropriateness of antimicrobial therapy measured by repeated prevalence surveys. Antimicrob Agents Chemother. 2007;51:864-7.

35. Swanson JM, Wells DL. Empirical Antibiotic Therapy for Ventilator-Associated Pneumonia. Antibiotics. 2013;2(3):339-51.

36. Luna CM, Aruj P, Niederman MS, Garzon J, Violi D, Prignoni A, et al. Appropriateness an delay to initiate therapy in ventilator-associated pneumonia. Eur Respir J. 2006;27:158-64.

37. Leibman V, Martin ET, Jasper RT, Grin L, Hayakawa K, Shefler C, et al. Simple bedside score to optimize the time and the decision to initiate appropriate therapy for carbapenem-resistant Enterobacteriaceae. Ann Clin Microbiol Antimicrob. 2015;14:31.
38. Al-Dorzi HM, Asiri AM, Shimemri A, Tamim HM, Al Johani SM, Al Dabbagh T. Impact empirical antimicrobial therapy on the outcome of critically ill patients with Acinetobacter bacteremia. Ann Thorac Med. 2015;10(4):256-62.

39. Luna CM, Vujacich P, Niederman MS, Vay C, Gherardi C, Matera J, et al. Impact of BAL data on the therapy and outcome of ventilator-associated pneumonia. Chest. 1997;111(3):676-85.

40. Leone M, Bourgoin A, Cambon S, Dubuc M, Albanese J, Martin C. Empirical antimicrobial therapy of septic shock patients: adequacy and impact on the outcome. Crit Care Med. 2003;31(2):4627.

41. Alvarez-Lerma F. Modification of empiric antibiotic treatment in patients with pneumonia acquired in the intensive care unit. ICU-Acquired Pneumonia Study Group. Intensive Care Med. 1996;22(5):387-94.

42. Paul M, Shani V, Muchtar E, Kariv G, Robenshtok E, Leibovici L. Systematic review and metanalysis of the efficacy of appropriate empiric antibiotic therapy for sepsis. Antimicrob Agents Chemother. 2010;54(11):4851-63.

43. Falagas ME, Kasiakou SK, Rafailidis PI, Zouglakis G, Morfou P. Comparison of mortality of patients with Acinetobacter baumannii bacteraemia receiving appropriate and inappropriate empirical therapy. J Antimicrob Chemother. 2006:57:1251-4.

44. Erbay A, Idil A, Gözel MG, Mumcuoglu I, Balaban N. Impact of early appropriate antimicrobial therapy on survival in Acinetobacter baumannii bloodstream infections. Int J Antimicrob Agents. 2009;34:575-9.

45. Choi JY, Park YS, Kim CO, Park YS, Yoon HJ, Shin SY, et al. Mortality risk factors of Acinetobacter baumannii bacteraemia. Intern Med J. 2005;35:599-603.

46. Lemos EV, de la Hoz FP, Einarson TR, McGhan WF, Quevedo E, Castañeda $C$, et al. Carbapenem resistance and mortality in patients with Acinetobacter baumannii infection: systematic review and meta-analysis. Clin Microbiol Infect. 2014;20:416-23.

47. Xu L, Sun X, Ma X. Systematic review and meta-analysis of mortality of patients infected with carbapenem-resistant Klebsiella pneumoniae. Ann Clin Microbiol Antimicrob. 2017;16:18.

48. Zaragoza R, Artero A, Camarena JJ, Sancho S, González R, Nogueira $\mathrm{JM}$. The influence of inadequate empirical antimicrobial treatment on patients with bloodstream infections in an Intensive Care Unit. Clin Microbiol Infect. 2003;9:412-8.
Ready to submit your research? Choose BMC and benefit from:

- fast, convenient online submission

- thorough peer review by experienced researchers in your field

- rapid publication on acceptance

- support for research data, including large and complex data types

- gold Open Access which fosters wider collaboration and increased citations

- maximum visibility for your research: over 100M website views per year

At BMC, research is always in progress.

Learn more biomedcentral.com/submissions 